\title{
An Assessment of Wind Availability for Turbine Power Generation in Kano, Nigeria
}

\author{
Joseph Aidan \\ Department of Physics, Modibbo Adama University of Technology, Yola, Adamawa State, Nigeria
}

\begin{abstract}
The wind speed distribution of Kano can be assumed Weibull or normally distributed with 5\% significance level (95\% confidence level). The Kolmogorov-Smirnov (KS) and Anderson-Darling goodness-of-fit tests both accepted these distribution functions as their test statistics did not fall short of their critical values. The distribution functions may be used to determine with better accuracy the wind power potentials of Kano. With a FL30 turbine, close to 50\% of its installed capacity can be extracted and be running/available for almost $50 \%$ of the time it may be operated in a year. While other turbines like Vestas47 and NW100/19 were not found suitable for wind power generation in Kano.
\end{abstract}

Keywords: Distribution function, fittings, goodness-of-fit, turbine power, wind availability,

\section{Introduction}

In Nigeria, wind energy utilization is practically minimal and relatively insignificant [1]. Though turbines have been used as wind pumps still have not been made popular due to high installation and maintenance cost [2]. In 1984, major feasibility studies on windmills were undertaken by the UNDP with specific interest in small scale irrigation, domestic water pumping, livestock water supply and electric power generation but ended up as mere desktop study. This means that there is insufficient information about the wind's quantity, quality, distribution, and utilization that could possibly be used to determine its commercial viability for utility scale power generation [2].

In assessing the wind power potential of a candidate site the knowledge of the wind speed distribution of the site is necessary. This is because the power ratings of wind turbines are based on the probability distribution function that fits to the wind speed data of the location [3]. To generate electricity, a preliminary assessment based on available data is necessary. A preliminary assessment not only determines whether further effort is warranted, but also locates regions of significant potentials for further studies and investment opportunities [4]. Reliable site specific data on wind energy resource are needed by investors to make better investment decisions on wind power.

In this paper, the Weibull and the normal distribution functions were fitted onto a constructed histogram of the wind speed data of Kano and validated with some goodness-of-fit tests. Assessments of the wind availability and potential for utility-scale wind power generation at the hug heights of some selected wind turbines were done.

\subsection{Sources of data}

\section{Data and Data Analysis}

The mesa-scale 3-hourly records of wind speeds (measured in knots) at a height of $3 \mathrm{~m}$ with its station coordinates are collected from the Meteorological Department, Climate Investigation Unit of the Federal Ministry of Aviation, Lagos, Nigeria. The monthly average of the wind speed data were taken over a period of ten years (1978-1988). The Kano station is located at Latitude of $12.05^{\circ} \mathrm{N}$, Long: $8.533^{\circ} \mathrm{E}$ and at an altitude of $472 \mathrm{~m}$.

\subsection{Fitting of the Weibull distribution functions}

The probability density function $f(v)$ for the 2-parameter Weibull distribution [5] is given:

$$
\begin{gathered}
f(v)=\frac{k}{c}\left(\frac{v}{c}\right)^{k-1} \exp \left[-\left(\frac{v}{c}\right)^{k}\right] \\
v \geq 0 ; k, c>0
\end{gathered}
$$

where $k$ is the shape parameter which determines the shape of the Weibull distribution and $c$ is the scale parameter.

The cumulative function $F(v)$ is: 


$$
\begin{aligned}
& F(v)=1-\exp \left[-\left(\frac{v}{c}\right)^{k}\right] \\
& v \geq 0 \text { and } F(v: c, k)=0 \text { for } v<0
\end{aligned}
$$

An approximation widely accepted for the values of $k$ and $c$ for the 2-parameter Weibull distribution is given [6 \& 7] by:

$$
\begin{gathered}
k=\left(\frac{\sigma}{\bar{v}}\right)^{-1.086} \\
c=\bar{v} \frac{k^{2.6674}}{0.184+0.816 k^{2.73859}}
\end{gathered}
$$

where $\sigma$ is the standard deviation of the wind speed for the site. The value estimates of $k$ and $c$ provide accuracy better than $0.01 \%$.

\subsection{Fitting of the normal distribution function}

The density function of the normal distribution function $n(v)$ is given as:

$$
n(v)=\frac{1}{\sqrt{2 \pi} \sigma} \exp \left[-\frac{1}{2}\left(\frac{v-\mu}{\sigma}\right)^{2}\right] \quad 0 \leq v \leq \infty
$$

where $\mu=E(v)$ and $\sigma=\sqrt{\operatorname{var}(v)}$ are respectively the mean and standard deviation of $v$, and are the parameters of the distribution.

\subsection{Goodness-of-fit test}

The Kolmogorov-Smirnov (KS) and the Anderson-Darling (AD) goodness-of-fit tests were used to validate the fitted distribution functions. For the Weibull distribution, some of the Weibull properties [8] were additionally verified and these include:

I. The scale parameter c lies approximately at the $63^{\text {rd }}$ percentile.

II. The plot of the transformed sorted wind speed data:

$$
\ln \left\{\ln \left[\frac{1}{1-F(v)}\right]\right\} \text { against } \ln v
$$

$$
\text { where } F(v)=\frac{\operatorname{Rank}(v)-0.3}{n+0.4} \text { should be linear and an alternative estimator of } c \text { and } k \text {. }
$$

III. The transformation $Y=v^{k}$ should yield an exponential distribution with mean $\mu=c^{k}$.

III. The plots of the sample data against the predicted values should be linear and have a slope of unity

\subsubsection{Kolmogorov-Smirnov (KS) test}

The basic procedure of the KS test involves the comparison between the experimental cumulative frequency and an assumed theoretical distribution function. If the discrepancy is large with respect to what is normally expected from a given sample size, the theoretical model is rejected.

For a sample of size $n$ with arranged observed data in increasing order, stepwise cumulative frequency function is developed as follows [9]:

$$
S_{n}(v)=\left\{\begin{array}{lr}
0, & v<v_{1} \\
\frac{k}{n}, & v_{k} \leq v<v_{k+1} \\
1, & v \geq v_{n}
\end{array}\right.
$$

where $v_{1}, v_{2}, \ldots \ldots, v_{n}$, are the values of the ordered sample data. In the KS test the maximum difference between the theoretical model and the observed data is denoted by:

$$
D_{n}=\max \left|F(v)-S_{n}(v)\right|
$$

For a specified significance level $\alpha(5 \%)$, the KS test compares the observed maximum difference with the critical value $D_{n}^{\alpha}$. If the observed $D_{n}$ is less than the critical value $D_{n}^{\alpha}$, the proposed distribution is accepted at the specified significance level $\alpha$; otherwise, the distribution is rejected. The table for the critical value is given elsewhere [9]. 


\subsubsection{Anderson-Darling (AD) test} is given as:

The AD test statistics is distribution specific. The AD goodness-of-fit test for normal distribution [10]

$$
A D=\sum_{i=1}^{n} \frac{1-2 i}{n}\left\{\ln \left[F_{0}(v)\right]+\ln \left[1-F_{0}\left(v_{n+1-i}\right)\right]\right\}-n
$$

where $F_{o}$ is the normal cumulative distribution function with sample estimated parameters $(\mu, \sigma) ; v_{\mathrm{i}}$ is the ith sorted and standardized sample values; $n$ is the sample size $(n=114)$.

The null hypothesis, that the true distribution is $F_{o}$ with the assumed parameters, is then rejected (at $5 \%$ significance level) if the AD test statistics is greater than the critical value (CV) [10] i.e. Reject if:

$$
A D>C V=\frac{0.752}{1+\frac{0.75}{n}+\frac{2.25}{n^{2}}}
$$

The Weibull version of the AD goodness-of-fit test is given as [10]:

and

$$
\begin{aligned}
A D & =\sum_{i=1}^{n} \frac{1-2 i}{n}\left\{\ln \left[1-\exp \left(-z_{i}\right)\right]-z_{n+1-i}\right\}-n \\
A D^{*} & =\left(1+\frac{0.2}{\sqrt{n}}\right) A D
\end{aligned}
$$

where $z_{i}=\left(\frac{v}{c}\right)^{k}$. At $5 \%$ significance, reject if OSL (observed significance level) $<0.05$ [10].

$$
O S L=1 /\left\{1+\exp \left[-0.1+1.24 \ln \left(A D^{*}\right)+4.48\left(A D^{*}\right)\right]\right\}
$$

\subsection{Wind availability}

Wind availability (WA) for greater than $50 \%$ turbine capacity generation gives the percentage of the available wind that can drive a wind turbine to generate at least $50 \%$ of its installed capacity at any particular instant at its designed hub height $h$. This is determined for a site from:

$$
W A=\int_{v_{50}}^{v_{\text {out }}} f(v) d v
$$

\begin{tabular}{|c|c|c|c|c|c|c|}
\hline Turbine & $\begin{array}{c}P_{r} \\
(\mathrm{~kW})\end{array}$ & $\begin{array}{c}v_{\text {in }} \\
\left(\mathrm{ms}^{-1}\right)\end{array}$ & $\begin{array}{l}v_{\text {out }} \\
\left(\mathrm{ms}^{-1}\right)\end{array}$ & $\begin{array}{c}v_{50} \\
\left(\mathrm{~ms}^{-1}\right)\end{array}$ & $\begin{array}{l}\text { Rotor diameter } \\
(\mathrm{m})\end{array}$ & $\begin{array}{l}\mathrm{Hub} \\
(\mathrm{m})\end{array}$ \\
\hline Proven & 2.5 & 2.5 & 20 & 6.50 & 3.5 & 11 \\
\hline Proven & 6.0 & 2.5 & 16 & 8.00 & 5.5 & 15 \\
\hline Bergey & 10.0 & 3.1 & 20 & 8.94 & 7 & 24 \\
\hline FL30 & 30.0 & 2.5 & 25 & 6.71 & 13 & 24 \\
\hline FL100 & 100.0 & 2.5 & 25 & 8.05 & 21 & 31 \\
\hline NW100/19 & 100.0 & 4.0 & 25 & 9.00 & 19.4 & 37 \\
\hline Vestas 27 & 225.0 & 4.6 & 29 & 10.24 & 27 & 31 \\
\hline Vestas47 & 660.0 & 4.6 & 29 & 10.13 & 47 & 55 \\
\hline
\end{tabular}

where $v_{50}$ is the minimum wind speed required by a turbine to produce at least $50 \%$ of its installed capacity at Kano and $v_{\text {out }}$ is the cut-out wind speed of a turbine.

The wind availability has been determined for some wind turbines that may be installed in Kano at the manufacturers' hub heights. The turbines used are presented alongside their specifications in Table 1.

Table 1: Wind Turbine Types and Specifications

\subsection{Wind power}

The $3 \mathrm{~m}$ height measured wind speeds may not be sufficient to set turbines into mechanical rotation. Hence wind speeds at greater heights have been predicted. This method has been used by other wind energy researchers [11,12]. Since the distribution of the wind speed $v$ in Kano is shown to be Weibull in addition to its being normally distributed, its special property is that the wind speed $v$ raised to the power of $m$ is also Weibull [13]. Therefore the Hellman power law has been used to predict the wind speeds at the specify turbine hub heights (Table 1). Details of this law can be found elsewhere [14, 15].

In assessing the wind power potentials of a candidate site, it is the root-mean-cube (rmc) wind speed that is considered. This is because different stations may have the same average wind speed but different rmc power densities. Given the Weibull distribution in equation (1), the expectation value of the wind speed is:

$$
\bar{v}=c \Gamma\left(1+\frac{1}{k}\right)
$$

where $\Gamma$ is the gamma function. Also the rmc speed $v_{r m c}$ of the Weibull is given by: 


$$
v_{r m c}=\left[c^{3} \Gamma\left(1+\frac{3}{k}\right)\right]^{\frac{1}{3}}
$$

Therefore, the site's rmc power density $\mathrm{P}_{\mathrm{s}}(\mathrm{W})$ is:

$$
\begin{aligned}
& P_{s}(W)=\frac{1}{2} \rho C_{p} v_{r m c}^{3} \\
& =\frac{1}{2} \rho C_{p} c^{3} \Gamma\left(1+\frac{3}{k}\right)
\end{aligned}
$$

The speed at which the wind is blowing most of the time is given by the modal speed, $v_{m}$ :

$$
v_{\text {mode }}=c\left(\frac{k-1}{k}\right)^{\frac{1}{k}}, k>1
$$

For the normal distribution, the site's rmc wind speed is

$$
v_{r m c}=\left\{\int_{0}^{\infty} v^{3} n(v) d v\right\}^{\frac{1}{3}}
$$

Therefore, the site power is

$$
P_{s}(N)=\frac{1}{2} C_{p} \rho\left\{\frac{1}{\sqrt{2 \pi}}\left(2 \sigma^{3}+3 \sigma \mu^{2}\right)+\frac{1}{2}\left(\mu^{3}+6 \mu \sigma^{3}\right)\right\}
$$

To determine wind power potential, the knowledge of the average air density of a location is necessary. This variation can be found elsewhere [3].

\subsection{Results of the fitted distribution functions}

\section{Results and Discussion}

The sample estimated parameters of the Weibull determined from equations $(3 \& 4)$ and those of the normal distribution functions which are the mean and standard deviation of the $3 \mathrm{~m}$ height (reference) wind speed data of Kano are presented in Table 2. Fig. 1 (a \& b) and Fig. 2 ( a \& b) show the fitted Weibull and normal probability distribution functions (pdf) onto the constructed frequency diagram (histogram) of the observed wind speed data alongside their corresponding cumulative distribution function (cdf) respectively.

Table 2:- Estimates of the parameters of the Weibull and normal distribution functions

\begin{tabular}{ccccccc}
\hline \multicolumn{2}{c}{ Weibull (GM) } & \multicolumn{3}{c}{ Weibull (MM) } & \multicolumn{3}{c}{ Normal distribution } \\
$\mathrm{k}$ & $\mathrm{c}$ & $\mathrm{k}$ & $\mathrm{c}$ & $\mu$ & \multicolumn{2}{c}{$\sigma$} \\
\hline 6.754 & 4.692 & 6.641 & 4.706 & 4.390 & 0.768 \\
\hline
\end{tabular}

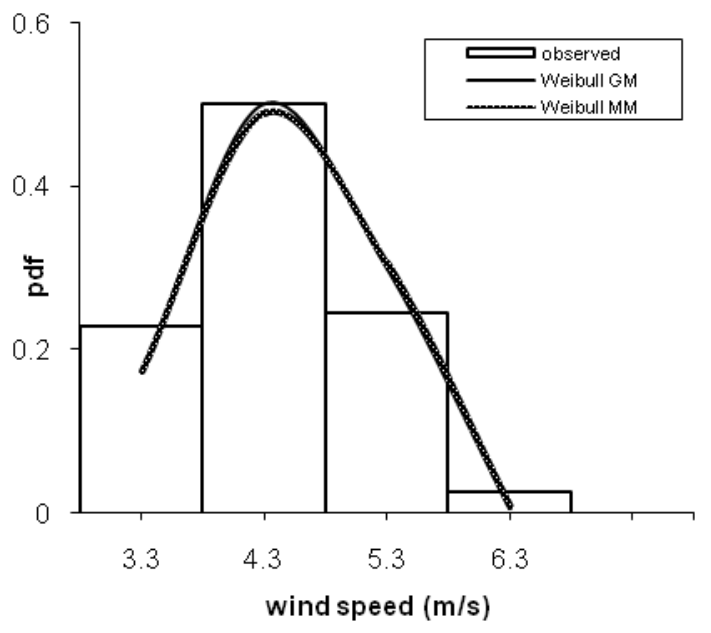

(a)

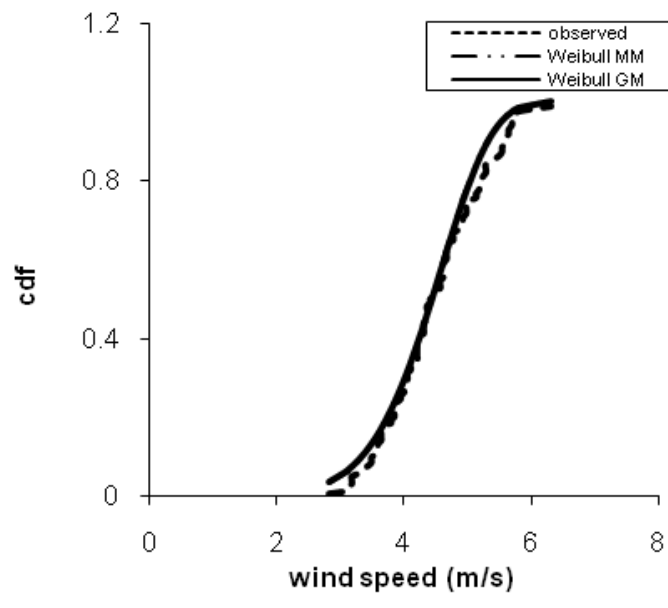

(b)

Figure 1: Fitted pdf (a) and cdf (b) for the Weibull distribution function 


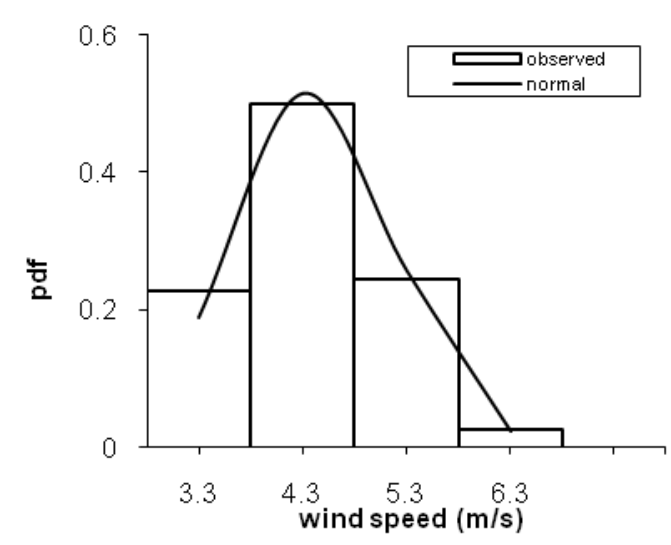

(a)

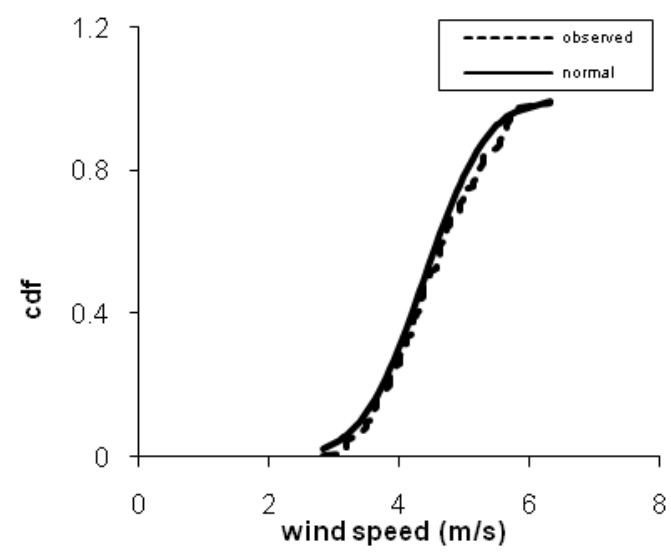

(b)

Figure 2: (a) Fitted pdf (a) and cdf (b) for normal distribution function

\subsection{Weibull properties verification and results of the goodness-of-fit tests}

Property I: after the data had been sorted in ascending order of magnitude, the $63^{\text {rd }}$ percentile $=4.6296$ $\cong$ value of c (=4.7065 from equation (4))

Property II: From Fig. 3, the slope is $6.754 \equiv$ k (compares with that obtained from equation (3)) and the estimates of $c(=4.6915)$ from the graph compares with those of property I and from equation (4)

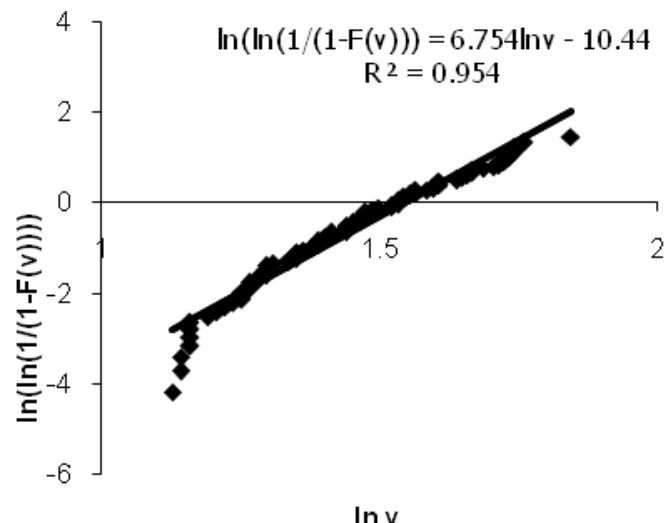

(a)

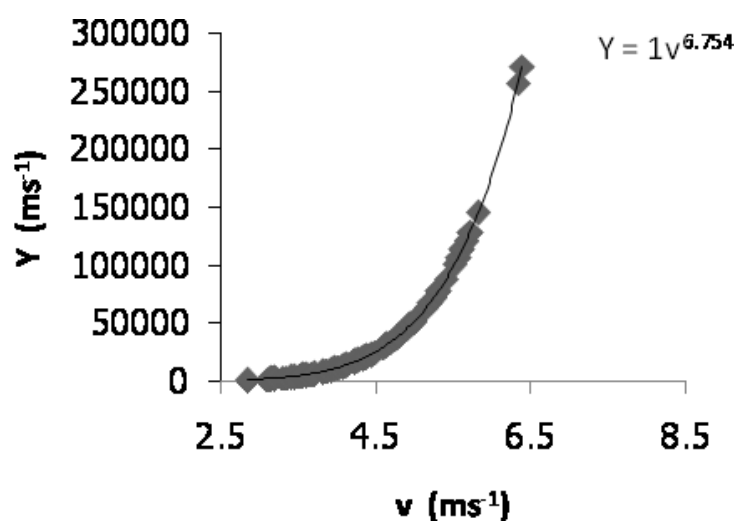

(b)

Figure 3:- The graph of $\ln (\ln (1 /(1-\mathrm{F}(\mathrm{v}))))$ against $\operatorname{lnv}(\mathrm{a})$ and the Exponential characteristics of property III (b). Property III: $\mu=37385.41$ from data and $\mu=c^{k}=4.6915^{6.754}=34201.04$-compares with only about $8.5 \%$ error. Property IV:

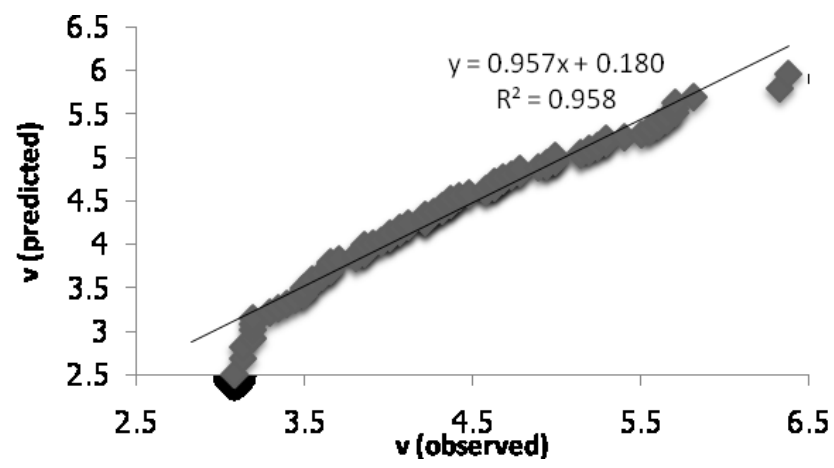

Figure 4:- Plots of the observed and the predicted wind speed data. 
Table 3:- Goodness-of-fit test results

\begin{tabular}{lllllll}
\hline Distribution & \multicolumn{3}{c}{ Kolmogorov-Smirnov test } & \multicolumn{3}{c}{ Anderson-Darling test } \\
function & $D_{n}$ & $D_{n}^{\alpha}$ & Decision & $\mathrm{AD}$ & OSL/CV & Decision \\
\hline Weibull & 0.0795 & 0.127 & accept & 0.345 & 0.456 & accept \\
normal & 0.0807 & 0.127 & accept & 0.487 & 0.747 & accept \\
\hline
\end{tabular}

It is clear from both the verified properties of the Weibull of section 3.2 and the results of the goodness-of-fit tests presented in Table 3 that the wind speed distribution of Kano is a good approximation of both the Weibull and the normal distribution functions with at least an associated 5\% significance level. From the KS test both the maximum difference obtained from the distribution functions are less than their critical values (i.e. $0.0795,0.0807<0.127$ ). This is also a clear acceptance of the fitted distribution functions; the AD test though distribution specific were very much accepted since OSL $>0.05$ for the Weibull and AD $<$ CV for the normal distribution function.

Additionally, Fig. 3(b) and Fig 4 represent proofs of the properties of the Weibull as theoretically suggested in section 2.4. Apart from the facts that Fig. 3(b) produced the exponential distribution as transformed, Fig. 4 provided a value of 0.958 for the slope which may be approximated to unity as property IV required. Therefore, either these tests or the KS and the AD tests have sufficiently verified that the data is Weibull distributed.

\subsection{Wind availability and power}

The average wind speed of $5.59 \mathrm{~ms}^{-1}$ is predicted from the Hellman power law at a height $10 \mathrm{~m}$ with the $3 \mathrm{~m}$ height measured wind speed data as reference. For classification purposes, Kano is therefore a potentially class 4 wind site and by extension a suitable site for utility power generation. It is to be noted that for the predicted wind speeds at various heights, fixed shape parameter of 6.754 was estimated but different scale parameters. The scale parameters, c for the fitted Weibull are shown in Table 4.

Table 4 also gives the predicted values of the mean, mode and root-mean-cube wind speed of Kano with their corresponding power densities at heights $11,15,24,31,37$ and $55 \mathrm{~m}$. it is clear that representation of a site's power with an average/mean power is an under estimation of the site's actual power. The root-meancube power $P_{s}$ has been shown to be greater than the mean power $P_{\text {mean }}$. The $P_{\text {mode }}$ indicates the wind power that can be extracted most of the time at the site and at the given heights. Therefore turbines whose rated wind speed falls within the modal speeds would be the most suitable for utility-scale power generation in Kano.

Table 4: The predicted mean, mode and rmc wind speed and their corresponding power densities at various heights.

\begin{tabular}{|c|c|c|c|c|c|c|}
\hline Hub height & $11 \mathrm{~m}$ & $15 \mathrm{~m}$ & $24 \mathrm{~m}$ & $31 \mathrm{~m}$ & $37 \mathrm{~m}$ & $55 \mathrm{~m}$ \\
\hline$\sigma$ & 0.996 & 1.060 & 1.164 & 1.225 & 1.269 & 1.374 \\
\hline $\mathrm{k}$ & 6.641 & 6.641 & 6.641 & 6.641 & 6.641 & 6.641 \\
\hline $\mathrm{c}\left(\mathrm{ms}^{-1}\right)$ & 6.103 & 6.494 & 7.134 & 7.508 & 7.779 & 8.421 \\
\hline$\rho$ & 1.224 & 1.223 & 1.222 & 1.221 & 1.221 & 1.218 \\
\hline$\mu\left(\mathrm{ms}^{-1}\right)$ & 5.693 & 6.058 & 6.655 & 7.004 & 7.256 & 7.855 \\
\hline$v_{r m s}\left(\mathrm{~ms}^{-1}\right)$ & 5.861 & 6.236 & 6.851 & 7.210 & 7.470 & 8.087 \\
\hline$v_{\text {mode }}\left(\mathrm{ms}^{-1}\right)$ & 5.955 & 6.336 & 6.961 & 7.326 & 7.590 & 8.216 \\
\hline$P_{\text {mean }}\left(\mathrm{Wm}^{-2}\right)$ & 56.455 & 67.975 & 90.041 & 104.914 & 116.596 & 147.646 \\
\hline$P_{\text {mode }}\left(\mathrm{Wm}^{-2}\right)$ & 64.602 & 77.785 & 103.036 & 120.056 & 133.424 & 168.954 \\
\hline$P_{s}(W)\left(\mathrm{Wm}^{-2}\right)$ & 61.591 & 74.160 & 98.234 & 114.460 & 127.205 & 161.080 \\
\hline$P_{s}(N)\left(\mathrm{Wm}^{-2}\right)$ & 63.277 & 76.189 & 100.922 & 117.592 & 130.686 & 165.487 \\
\hline
\end{tabular}

Table 5: Extractible wind power and wind availability for some selected wind turbines

\begin{tabular}{ccccccc}
\hline $\begin{array}{c}\text { Turbine } \\
\text { type }\end{array}$ & $\begin{array}{c}v_{50} \\
\left(\mathrm{~ms}^{-1}\right)\end{array}$ & $\begin{array}{c}\text { Swept area } \\
\left(\mathrm{m}^{2}\right)\end{array}$ & \multicolumn{2}{c}{$\begin{array}{c}\text { Extractible power }(\mathrm{kW}) \\
\text { normal }\end{array}$} & Weibull & \multicolumn{2}{c}{ Wind Availability $(\%)$} \\
Normal & Weibull \\
\hline Proven & 6.50 & 9.62 & 0.61 & 0.59 & 20.89 & 21.88 \\
Proven & 8.00 & 23.76 & 1.81 & 1.76 & 3.36 & 1.84 \\
Bergey & 8.94 & 38.49 & 3.88 & 3.78 & 2.48 & 1.14 \\
FL30 & 6.71 & 132.75 & 13.40 & 13.04 & 48.12 & 51.39 \\
FL100 & 8.05 & 346.41 & 40.74 & 39.65 & 19.66 & 20.42 \\
NW100/19 & 9.00 & 295.63 & 38.63 & 37.61 & 8.48 & 7.18 \\
Vestas27 & 10.24 & 572.63 & 67.34 & 65.54 & 0.41 & 0.04 \\
Vestas47 & 10.13 & 1735.17 & 287.15 & 279.50 & 6.85 & 3.30 \\
\hline
\end{tabular}


Table 5 shows the suitability of some selected wind power turbines in Kano. This suitability is indicated in terms of the values of the extractible power a turbine can have at the site and its corresponding wind availability for at least $50 \%$ capacity generation. The most suitability wind turbine is the Fuhrlander FL 30 . This study has shown that FL30 can extract close to $50 \%$ of its installed capacity and be available for almost $50 \%$ of the time it may be operated. On the other hand, turbines like Vestas 47 and NW100/19 may be capable of extracting close to $50 \%$ of its installed capacity but lacks the wind to offer this capacity generation for $50 \%$ of its operating time because the wind (about 3.30\%) to run these turbines is almost not available at the hub height of 55 or $42 \mathrm{~m}$ respectively.

\section{Conclusion}

For the purpose of the determination of the wind energy potential of Kano, the wind speed distribution can be assumed Weibull or normally distributed with about $95 \%$ confidence level. Utility-scale wind power generation may be possible in Kano. At a height of 30 m, Fuhrlander FL 30 may be suitable. At least $15 \mathrm{~kW}$ can be generated for about $50 \%$ of its operating time over a year. A wind farm sited in Kano using FL30 turbines might add a tremendous amount of electrical energy to the grid system.

\section{References}

[1] E. E. Iheonu, F. O. A. Akingbade and M. Ocholi, Wind resource variations over selected site in the west african sub -region, Nigerian Journal of Renewable Energy, 10(1\&2), 2002, 43-47.

[2] Energy Commission of Nigeria, Report on Renewable Energy, (Master Plan, 2005).

[3] M. R. Patel, Wind and Solar Power Systems (CRC press LLC, 1999).

[4] R. Karen, An Assessment of the Potential for Utility-Scale Wind Power Generation in Eritrea. M.Sc. Thesis, 1998.

[5] W. Weibull, A statistical distribution function of wide applicability, J. Appl. Mech.-Trans, 18(3) ASME 1951, $293-297$.

[6] W. R. Justus, W. R. Harngraves and A. Yalcin, Nationwide assessment of output from wind power generators, Journal of Applied Meteorology, 15, 1976, 673-678.

[7] A. Balouktisis, D. Chassapis and T. D. Karapantsios, A nomogram method for estimating the energy produced by wind potential generators, Solar Energy, 72(3), 2002, 251- 259.

[8] J. L. Romeu, Empirical assessment of Weibull distribution, RAC START, 10, 3. (http://rac.alionscience.com).

[9] H. S. Aifredo and H. T. Wilson, Probability concepts in engineering planning and design (John Wiley \& Sons, Inc., 1975).

[10] J. L. Romeu, Anderson-Darling: A goodness-of-fit test for small samples assumptions, RAC START, 10, 5. (http://rac.alionscience.com)

[11] A. A. Ahmed, F. Ahmad and M. W. Akhtar, Assessment of wind power potential for coastal areas of Pakistan, Turkish Journal of Physics, 30, 2006, 127-135.

[12] S. Rehman and A. Ahmad, Assessment of wind energy potential for the kingdom of Saudi Arabia Energy 29, 2004, $1105-1115$.

[13] B. G. Brown, R. W. Katz and A. H. Murphy, Time series models to simulate and forecast wind speed and wind power, Journal of Climate and Applied Meteorology, 23, 1984, 1184-1195.

[14] S. Hellmann and M. Roseinstein, Normal monthly wind stress over the world ocean with error estimates, Journal of Physical Oceanography, 13, 1983, 1093-1104.

[15] J. Aidan and J. C. Ododo, Wind energy potential of some northern Nigerian cities, Nigerian Journal of Solar Energy, 19(2), 2008, 49-53. 